unemployed individuals have more flexible time schedules for keeping appointments.

By concentrating on established attenders to the service, we understood the fear of clinicians to be well grounded, i.e. "is the known individual who has missed an appointment likely to re-contact the service?". Put another way, who among the nonattenders has been seen unwittingly for the last time? Is this cause for relief or concern.?

In general terms our study demonstrated that patients lost to follow-up are less ill, more likely to be employed and more likely to have the support of a marital relationship, and as such this is not a cause for concern. However in economic terms, failure to attend the clinic is wasteful in terms of staff time and may result in unnecessary home visits.

The role of out-patient services has gradually changed over the years from being an adjunct to inpatient treatment (Kessel \& Hassall, 1965) to having adopted a more independent role and being engaged in the diagnosis and treatment of a wide range of psychiatric disorders (Johnson, 1973). It is important to establish which patients fail to make use of the service so that the out-patient resources are fully utilised, and so that alternative provision can be made for those patients who do not make full use of the existing services.

Further prospective studies will be required to establish more information about patients who are lost to follow-up, than we have been able to report in this retrospective study.

The results of this study are relevant to the optimum utilisation of resources as different services for different client populations evolve.

\section{References}

BaEkland, F. \& Lundwall, L. (1975) Dropping-out of treatment: a critical review. Psychological Bulletin, 82, 738-783.

BURGESS, J. \& HARRINGTON, J. (1964) 200 psychiatric outpatient non-attenders. Case Conference, 11, 58-60.

ENDICOTT, N. \& ENDICOTT, J. (1964) Improvement in untreated psychiatric patients. Archives of General Psychiatry, 9, 575-585.

FRIEDMAN, M. \& WEST, A. (1987) Current need versus treatment history as predictors of use of out-patient care. American Journal of Psychiatry, 144, 355-357.

GotTschalk, L., Fox, R. \& Bates, D. (1973) A study of prediction and outcome in a mental health crisis clinic. American Journal of Psychiatry, 130, 1007-1011.

JoHNSON, D. (1973) An analysis of out-patient services. British Journal of Psychiatry, 122, 301-306.

Kessel, N. \& Hassall, C. (1965) Psychiatric out-patients in Plymouth - an area service analysed. British Journal of Psychiatry, 111, 10-17.

LEWIS, G. \& APPLEBY, L. (1988) Personality disorders: the patients psychiatrists dislike. British Journal of Psychiatry, 153, 44-49.

SKUSE, D. (1975) Attitudes to the psychiatric out-patient clinic. British Medical Journal, 3, 469-471.

\title{
Rejection of psychiatric treatment
}

\author{
Graham Hillis, 4th Year Medical Student, Medical School, University of Aberdeen; \\ and David A. Alexander, Senior Lecturer in Mental Health, Department of \\ Mental Health, University Medical Buildings, Foresterhill, Aberdeen AB9 2ZD \\ (correspondence)
}

The growing realisation that health care resources are limited has led to increasing concern about the wastage caused by the failure of patients to keep their psychiatric appointments. Generally, nonattendance following psychiatric referral is particularly high (e.g. Baekland \& Lundwall, 1975), although in the north-east of Scotland the rate is roughly similar to those reported by other specialties (Alexander \& Hillis, 1989). However, little effort has been made to elicit the views of non-attenders them- selves or to consider what aspects of the referral system may contribute to this failure to attend.

The aims of this study were to: identify features which distinguish those patients who failed to keep their appointments following referral from general practitioners; and establish the views of nonattenders.

The computerised records of the Grampian Adult Psychiatric services were used to identify all 129 patients referred by their general practitioners during 
1986, but who failed to keep their first ever, or any subsequent, psychiatric appointment with this service. A computerised program randomly selected a comparison group of 100 patients, who attended their initial appointment. On the basis of casenote data $\chi^{2}$ analyses were conducted to compare the two groups on the following items: age, sex, marital status, socio-economic status, distance to travel for appointment, style of appointment (i.e. personal letter or formal appointment card), location of appointment (i.e. hospital or health centre), and previous psychiatric history (with another service).

In addition, an anonymous postal questionnaire (covering reasons for non-attendance) was sent to all patients who did not attend their appointments, excluding 17 who were suffering from organic or major functional psychoses. These individuals were omitted because the results of the pilot study confirmed the poor reliability of their replies. A response rate of $40 \%$ was obtained. This compared favourably with similar projects (e.g. Carpenter et al, 1981).

Only three factors significantly differentiated 'attenders' from 'non-attenders'. Patients were more likely to attend if:

(a) they received a personal letter rather than a standard appointment card $(P<0.05)$

(b) they had a previous psychiatric history $(P<0.05)$ and

(c) their appointment had been at a health centre rather than at a psychiatric hospital $(P<0.02)$.

While $60 \%$ of patients claimed that their GPs had encouraged them to attend, the same number doubted whether their doctors thought their referral would be of any benefit. Furthermore, only $44 \%$ stated that their GPs had helped them understand their condition and, most strikingly, only $6 \%$ were of the opinion that the need for a psychiatric referral had been sufficiently explained to them by their family doctors.

About half the respondents claimed that the 'poor image' of psychiatry, the prospect of talking about 'embarrassing things' (particularly in front of others, such as medical students), and the fact that they felt better had contributed significantly to their nonattendance. A third of them also reported that the need to take time off work, doubts about the relevance of treatment, fears of being put in hospital, and concerns about how others would regard them had been major deterrents to keeping their appointments.

\section{Comment}

The present data suggest that socio-demographic factors do not play a significant part in nonattendance. This contrasts with the findings of many
American studies which predominate in this field. However, the location of the appointment was relevant in that those referred to see psychiatrists at health centres were significantly more likely to keep their appointments, adding weight to the claim that psychiatric clinics in primary care settings are more acceptable to patients. Also, the more personal approach, by means of a letter rather than a standard and impersonal appointment card, seemed to have been more effective in encouraging patients to attend. The increased attendance of those with a psychiatric history suggests that once the patient has accepted that he/she has a psychiatric problem it may make it easier to respond appropriately to subsequent referrals. Some comfort can also be drawn from this finding because it implies that their previous contact had not been a deterrent.

Other themes which emerged indicate the need for patients to be given clear information about the reasons for, and the value of, psychiatric referral. Earlier studies have shown that patients are often dissatisfied with the quality of the information that they are given (Editorial, 1972) and that compliance with medical advice is significantly linked with fulfilment of an expectation of explanation (Francis et al, 1969). Thus GPs must be urged to provide adequate information and encouragement and, therefore, reduce some of the concerns which seem to be powerful deterrents to the acceptance of psychiatric referral.

\section{Acknowledgements}

We wish to thank Mr David Hunter, Systems Analyst, Psychiatric Case Register, the staff of the Grampian Mental Health Services Records Department; the general practitioners of Grampian region for their invaluable assistance in this study, and the consultants who gave us access to the casenotes.

\section{References}

AleXANDER, D. A. \& Hillis, G. (1989) Referrals to hospital by general practitioners. British Medical Journal, 298, 48. BAEKLAND, F. \& LuNDWALL, L. (1975) Dropping out of treatment: a critical review. Psychological Bulletin, 82, 738-783.

Carpenter, P. J., Morrow, G. R., Del Gaudio, A. C. \& RizLER, B. A. (1981) Who keeps the first outpatient appointment? American Journal of Psychiatry, 131, 101-105.

EDITORIAL (1972) The patient's point of view. Journal of the Royal College of General Practitioners, 22, 810.

Francis, V., Korsch, B. M. \& Morris, M. J. (1969) Gaps in doctor-patient communication. New England Journal of Medicine, 280, 535-540. 